\title{
Effectiveness of Duloxetine Monotherapy Compared to Combination Therapy with Other Antidepressants in Patients with Major Depressive Disorder: A Short-Term, Retrospective Study
}

\author{
Eun-Jin Cheon', Jun-Yeob Lee ${ }^{2}$, Joong-Hyeon Choi' ${ }^{1}$ Young-Ji Lee', and Bon-Hoon Koo ${ }^{1 凶}$ \\ 'Department of Psychiatry, Yeungnam University College of Medicine, Yeungnam University Medical Center, Daegu, Republic of Korea \\ ${ }^{2}$ Department of Psychiatry, Saebits Hospital, Gyeongju, Republic of Korea
}

\begin{abstract}
Objective The purpose of this study was to compare duloxetine monotherapy to combination therapy with other antidepressants in patients with major depressive disorder in a clinical, real world setting.

Methods An eight-week, retrospective, multi-center study of outpatients with major depressive disorder was undertaken. After screening 415 patients, enrolled in this study from July 2009 to June 2014 were 82 patients from among three centers who had been taking duloxetine with or without other antidepressant and not administered with atypical antipsychotics. We compared the mean changes of the Clinical Global Impression-Severity Scale (CGI-S) as a primary measure and the discontinuation rate as a secondary measure between the duloxetine monotherapy group $(n=36,43.9 \%)$ and the combination therapy with other antidepressants group $(n=46,56.1 \%)$ at baseline, one, two, four and eight weeks.

Results There were no significant differences across the demographic characteristics between two groups. There was, however, a statistically greater improvement on the CGI-S at weeks 2, 4 and 8 in the combination group compared with the monotherapy group. There were no significant differences in discontinuation rate and adverse events between two groups. No serious adverse events were reported in both groups during the study period.

Conclusion This result suggests that the duloxetine combination therapy with other antidepressants could improve effectiveness and have comparable tolerability with the monotherapy in the treatment of outpatients with major depressive disorders in a naturalistic setting. Adequately powered, well-controlled clinical trials are strongly warranted to confirm our findings due to methodological shortcomings.

Psychiatry Investig 2016;13(4):447-452
\end{abstract}

Key Words Duloxetine, Combination therapy, Major depressive disorder.

\section{INTRODUCTION}

Antidepressant medications, when used as monotherapies in placebo-controlled registration trials, typically result in $30 \%$ to $35 \%$ remission rates. ${ }^{1,2}$ Currently available results from placebo-controlled clinical trials and practical clinical studies, such as the Sequenced Treatment Alternatives to Relieve Depression (STAR*D), have demonstrated weak or limited efficacy of antidepressant treatment for major depressive dis-

Received: June 24, 2015 Revised: October 27, 2015

Accepted: October 27, 2015 Available online: March 23, 2016

$\triangle$ Correspondence: Bon-Hoon Koo, MD, PhD

Department of Psychiatry, Yeungnam University College of Medicine, $170 \mathrm{Hy}$ eonchung-ro, Nam-gu, Daegu 42415, Republic of Korea

Tel: +82-53-620-3343, Fax: +82-53-629-0256, E-mail: vijnana@chol.com

(a) This is an Open Access article distributed under the terms of the Creative Commons Attribution Non-Commercial License (http://creativecommons.org/licenses/bync/3.0) which permits unrestricted non-commercial use, distribution, and reproduction in any medium, provided the original work is properly cited. order. $^{3}$ Therefore, providing more diverse treatment options for such patients should enhance treatment outcomes in clinical practice. For example, augmenting with other psychotropics, combining different antidepressants, and switching to different antidepressants may be viable treatment options for major depressive disorder patients who fail to show beneficial responses to initial standard antidepressant treatment. ${ }^{4}$

Although widely used and usually safe, the efficacy of even the most widely prescribed combinations of antidepressants has not been established by properly controlled and adequately powered clinical trials. ${ }^{5}$ In this issue, Blier and colleagues reported on a six-week double-blind randomized trial among outpatients with nonpsychotic major depressive disorder. ${ }^{6}$ Mirtazapine combined with venlafaxine, bupropion or fluoxetine resulted in significantly greater sustained remission rates $(58 \%, 46 \%, 52 \%$, respectively) than fluoxetine plus a placebo (25\%). The combined use of two antidepressants was well 
tolerated and produced greater improvement than monotherapy. However, the results of the Combining Medications to Enhance Depression Outcomes (CO-MED) trial ${ }^{2}$ differed significantly from the earlier studies. The CO-MED trial compared two antidepressant combinations (escitalopram+bupropion and venlafaxine+mirtazapine) with escitalopram monotherapy to determine whether either combination would produce a higher remission rate at the end of a 12-week period and, secondarily, after 7 months in outpatients with chronic or recurrent major depression. Neither medication combination outperformed monotherapy. However, the combination of extended-release venlafaxine plus mirtazapine may have a greater risk of producing adverse events. The paucity of RCTs on combined $\mathrm{AD}$ strategies, coupled with inconsistencies in the findings of the studies that have been completed, justify the conclusion that this commonly used approach has not been adequately researched. ${ }^{5}$

Duloxetine, a serotonin and norepinephrine reuptake inhibitor (SNRI), has been found to be an effective acute and long-term treatment for patients with major depressive disorder. ${ }^{7-13}$ Additionally, pooled-analysis and meta-analysis have also reported comparative efficacy and safety of duloxetine with other antidepressants in patients with major depressive disorder. ${ }^{14,15}$ Another SNRI, venlafaxine, was included in the several studies evaluating combination strategies. ${ }^{2,6}$ However, duloxetine combination therapy with other antidepressants was seldom studied.

Therefore, the purpose of this study was to compare duloxetine monotherapy to combination therapy with other antidepressants in patients with major depressive disorder in a clinical, real world setting.

\section{METHODS}

\section{Subjects}

Inclusion criteria were age of at least 18 years, a DSM-IV-TR ${ }^{16}$ diagnosis of major depressive disorder and current treatment with duloxetine. Diagnoses were made on the basis of clinical assessments conducted by experienced, board certified psychiatrists. The exclusion criteria included dementia, mental retardation, head trauma, epilepsy, other organic mental disorders, participation in other clinical trials within 1 month and pregnancy or breast-feeding state. Patients receiving adjunct atypical antipsychotics with proven antidepressant effect were excluded from the analysis. All medications including duloxetine and other antidepressants were started and adjusted according to the treating clinician's experience and preference during the patients' study period. This study examined the medical records of 415 patients with major depressive disorder, through 3 centers, from July 2009 to June 2014.

\section{Procedures}

An eight-week, naturalistic, retrospective, multi-center study in outpatients with major depressive disorder was undertaken. The medical records of the 415 recruited patients were reviewed and evaluated by four board-certified psychiatrists. According to the inclusion and exclusion criteria, 82 patients were enrolled in this study. Demographic data, psychiatric history, concurrent medications, treatment effectiveness and adverse effects were recorded. Mean changes on the Clinical Global Impression-Severity scale (CGI-S) ${ }^{17}$ as a primary measure and the discontinuation rate as a secondary measure between duloxetine monotherapy group and combination therapy with other antidepressant groups at baseline, one, two, four and eight weeks were compared. Any occurrence of adverse events throughout the trial was reported. Nausea, dizziness, dry mouth, constipation, headache, perspiration, loss of appetite, somnolence, blurred vision, palpitation, fatigue were included to systematically collect data on adverse events. The degree of severity for each item was rated as mild, moderate or severe. The relationship between the adverse event and duloxetine treatment was assessed such as unlikely, possible, probable and definite. As a retrospective study, patient consent was exempted, and this study was approved by the hospital ethics committee.

\section{Statistical analysis}

Frequency analysis and descriptive analysis were used to examine the demographic characteristics and clinical features of the subjects. Variations in CGI-S were compared, thus indicating differences in treatment effects and drug tolerance between the administration of duloxetine alone for depressive disorder and combination treatment with other antidepressants. The subjects were divided into two groups and a repeated measure t-test was conducted. All statistical analyses used PASW Version 21.0 for Windows (Chicago, IL, USA). In each analysis, statistical significance was accepted when $\mathrm{p}<0.05$.

\section{RESULTS}

\section{Demographic and patient characteristics}

After screening 415 patients, 82 DSM-IV diagnosis of major depressive disorder patients from 3 centers according to the inclusion and exclusion criteria previously discussed herein enrolled in this study from July 2009 to June 2014.

There were no significant differences across patient demographic characteristics, physical and psychiatric comorbidities, family histories, family histories of attempted suicides, duration of illnesses, or mean baseline CGI scores between the two groups (Table 1 and 2). The dosage of duloxetine ranged from 30 to $90 \mathrm{mg} /$ day. The mean daily dosage of duloxetine 
Table 1. Socio-demographic \& clinical features of depressed patients $(\mathrm{N}=82)$

\begin{tabular}{|c|c|c|c|c|c|}
\hline \multirow{3}{*}{ Characteristic } & \multicolumn{4}{|c|}{ Patient group } & \multirow{3}{*}{$\mathrm{p}$} \\
\hline & \multicolumn{2}{|c|}{ Monotherapy $(\mathrm{N}=36)$} & \multicolumn{2}{|c|}{ Combination therapy $(\mathrm{N}=46)$} & \\
\hline & $\mathrm{N}$ & $\%$ & $\mathrm{~N}$ & $\%$ & \\
\hline Sex & & & & & 0.35 \\
\hline Male & 10 & 27.8 & 18 & 39.1 & \\
\hline Female & 26 & 72.2 & 28 & 60.9 & \\
\hline Occupation & & & & & 0.77 \\
\hline Employed & 31 & 86.1 & 38 & 82.6 & \\
\hline Unemployed & 5 & 13.9 & 8 & 17.4 & \\
\hline Marriage & & & & & 0.50 \\
\hline Single & 3 & 8.3 & 7 & 15.2 & \\
\hline Married & 30 & 83.3 & 38 & 82.6 & \\
\hline Divorce & 2 & 5.6 & 1 & 2.2 & \\
\hline Prior history of psychiatric medication & & & & & 0.51 \\
\hline $\mathrm{Y}$ & 19 & 52.8 & 28 & 60.9 & \\
\hline $\mathrm{N}$ & 17 & 47.2 & 18 & 39.1 & \\
\hline Family history of psychiatric illness & & & & & 0.50 \\
\hline $\mathrm{Y}$ & 5 & 13.9 & 4 & 8.7 & \\
\hline $\mathrm{N}$ & 31 & 86.1 & 42 & 91.3 & \\
\hline Family history of attempted suicide & & & & & 0.58 \\
\hline Y & 2 & 5.6 & 1 & 2.2 & \\
\hline \multirow[t]{2}{*}{$\mathrm{N}$} & 34 & 94.4 & 45 & 97.8 & \\
\hline & Mean & $\mathrm{SD}$ & Mean & SD & \\
\hline Age & 51.86 & 14.88 & 49.04 & 15.24 & 0.77 \\
\hline Education & 8.81 & 4.51 & 11.6 & 5.19 & 0.49 \\
\hline Disease duration (month) & 58.48 & 58.28 & 63.07 & 72.52 & 0.59 \\
\hline Duloxetine dose & 32.57 & 8.52 & 33.91 & 10.21 & 0.73 \\
\hline
\end{tabular}

was $32.6 \mathrm{mg} /$ day in the monotherapy group, $33.9 \mathrm{mg} /$ day in the combination therapy group, and there was no significant difference in the mean daily dosage at weeks 2,4 and 8 between the two groups.

With respect to the combination group, the most commonly prescribed antidepressant with duloxetine was mirtazapine followed by paroxetine $\mathrm{CR}$, escitalopram, venlafaxine, bupropion, sertraline and fluoxetine. 43 (93.5\%) out of 46 patients in combination group were prescribed with another antidepressant before 4 weeks.

\section{Clinical efficacy}

Overall, patients from both groups displayed gradual improvement (Table 3, Figure 1). There were statistically greater improvements on the CGI-S at weeks 2, 4 and 8 for the combination group compared with the monotherapy group $(\mathrm{p}=$ $0.03)$.

\section{Discontinuation rate}

There were no significant differences in discontinuation rate between two group (Figure 2). The causes of discontinuation was lost to follow up $(9,19.6 \%)$, adverse events $(3,6.5 \%)$, lack of effect $(3,6.5 \%)$ and hospitalization $(1,2.2 \%)$ in combination group. The incidence of adverse events that leads to discontinuation was not different significantly between two groups.

\section{Adverse effect}

The incidence of adverse events reported of patients is presented in Table 4 . While the majority of the adverse events were reported more frequently in the combination group, the difference was not statistically significant. The adverse events in both groups were ranged from mild to moderate. No serious adverse events were reported in both groups.

\section{DISCUSSION}

A recent systematic review and meta-analysis of antidepres- 
Table 2. Comorbid psychiatric and physical illness $(\mathrm{N}=82)$

\begin{tabular}{|c|c|c|c|c|c|}
\hline \multirow{3}{*}{ Illness variable } & \multicolumn{4}{|c|}{ Patient group } & \multirow{3}{*}{$\mathrm{p}$} \\
\hline & \multicolumn{2}{|c|}{ Monotherapy $(\mathrm{N}=36)$} & \multicolumn{2}{|c|}{ Combination therapy $(\mathrm{N}=46)$} & \\
\hline & $\mathrm{N}$ & $\%$ & $\mathrm{~N}$ & $\%$ & \\
\hline Comorbid Axis I disorders & & & & & 0.77 \\
\hline Dysthymic disorder & 8 & 22.2 & 11 & 23.9 & \\
\hline Anxiety disorder & 2 & 5.6 & 3 & 6.5 & \\
\hline Panic disorder & - & - & - & - & \\
\hline Social phobia & - & - & 1 & 2.2 & \\
\hline Somatoform disorders & 1 & 2.8 & 3 & 6.5 & \\
\hline Alcohol abuse & - & - & - & - & \\
\hline Substance dependence & 1 & 2.8 & 1 & 2.2 & \\
\hline $\mathrm{ADHD}$ & 1 & 2.8 & - & - & \\
\hline Impulse control disorder & - & - & 1 & 2.2 & \\
\hline Number of comorbid Axis I disorders & & & & & 0.78 \\
\hline 0 & 23 & 63.9 & 26 & 56.2 & \\
\hline 1 & 12 & 33.3 & 18 & 39.1 & \\
\hline$\geq 2$ & 1 & 2.8 & 2 & 4.3 & \\
\hline Comorbid Axis II disorders & & & & & 0.39 \\
\hline Borderline PD & 1 & 2.8 & 4 & 8.7 & \\
\hline Histrionic PD & 4 & 11.1 & 5 & 10.9 & \\
\hline Dependent PD & 1 & 2.8 & 1 & 2.2 & \\
\hline Obsessive compulsive PD & 2 & 5.6 & 2 & 4.3 & \\
\hline Number of comorbid Axis II disorders & & & & & 0.88 \\
\hline 0 & 27 & 75 & 34 & 73.9 & \\
\hline 1 & 7 & 19.4 & 11 & 23.9 & \\
\hline$\geq 2$ & 1 & 2.8 & 1 & 2.2 & \\
\hline Comorbid physical illness & & & & & 0.39 \\
\hline Hypertension & 1 & 2.8 & 3 & 6.5 & \\
\hline Glycosuria & 3 & 8.3 & 2 & 4.3 & \\
\hline Hypothyroidism & 1 & 2.8 & - & - & \\
\hline Asthma & - & - & 1 & 2.2 & \\
\hline Cardiovascular risk & 1 & 2.8 & 1 & 2.2 & \\
\hline Cerebropathia & 2 & 5.6 & 1 & 2.2 & \\
\hline Etc & 4 & 11.1 & 7 & 15.2 & \\
\hline
\end{tabular}

ADHD: attention deficit hyperactivity disorder, PD: personality disorder

Table 3. Changes in the Clinical Global Impression-Severity (CGI-S)

\begin{tabular}{|c|c|c|c|c|c|c|c|}
\hline \multirow{3}{*}{ Variables } & \multicolumn{4}{|c|}{ Patient group } & \multirow{3}{*}{$\mathrm{p}^{*}$} & \multirow{3}{*}{$\mathrm{p}^{\dagger}$} & \multirow{3}{*}{$\mathrm{p}^{\ddagger}$} \\
\hline & \multicolumn{2}{|c|}{ Monotherapy $(\mathrm{N}=36)$} & \multicolumn{2}{|c|}{ Combination therapy $(\mathrm{N}=46)$} & & & \\
\hline & Mean & SD & Mean & SD & & & \\
\hline \multicolumn{8}{|l|}{ CGI-S } \\
\hline Baseline & 4.11 & 0.71 & 4.22 & 0.76 & \multirow{4}{*}{$0.00^{*}$} & \multirow{4}{*}{$0.00^{*}$} & \multirow{4}{*}{0.03} \\
\hline 2 weeks & 3.67 & 0.83 & 3.26 & 0.77 & & & \\
\hline 4 weeks & 3.28 & 0.85 & 2.7 & 0.81 & & & \\
\hline 8 weeks & 2.75 & 0.97 & 2.2 & 0.81 & & & \\
\hline
\end{tabular}

${ }^{*} \mathrm{p}$ value of repeated measure ANOVA monotherapy group, ${ }^{\dagger} \mathrm{p}$ value of repeated measure ANOVA combination therapy group, ${ }^{\ddagger} \mathrm{p}$ value of repeated measure ANOVA monotherapy group and combination therapy group 
sant combination therapy suggests that combined antidepressants may be more efficient in the treatment of major depressive disorder than monotherapy, but the small number of trials and methodological drawbacks preclude definitive conclusions about the efficacy and tolerability of the use of antidepressant combinations. ${ }^{18}$

Moreover, the studies on combined antidepressant strategies present inconsistent results, which are classified as follows:

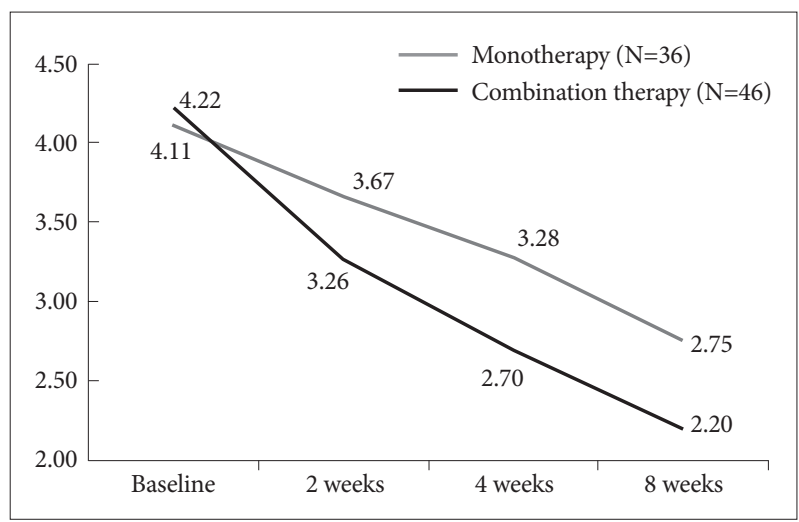

Figure 1. Changes in the Clinical Global Impression-Severity.

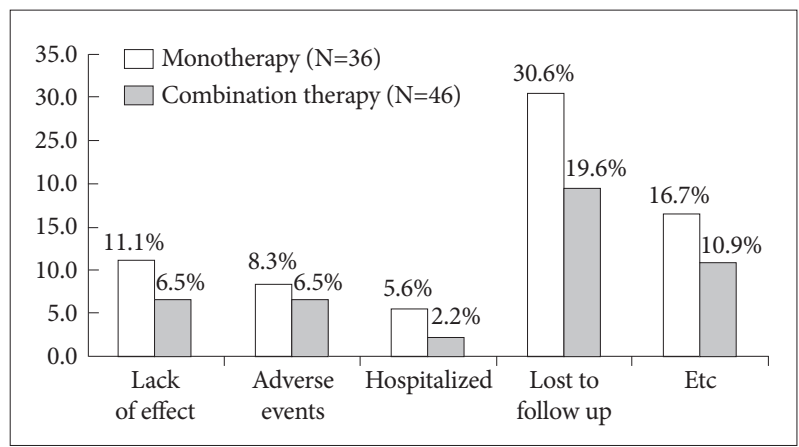

Figure 2. Discontinuation rate.
Group 1)-combination therapy with superior efficacy and comparable tolerability with monotherapy; Group 2)-combination therapy with superior efficacy and inferior tolerability with lower attrition; and Group 3)-combination therapy with similar efficacy and inferior tolerability with monotherapy. These inconsistencies in the results may be due to differences in dosages, in patient characteristics or in the antidepressant combination regimen. In some cases, it is possible to raise questions about the dosage of the single antidepressant group. For example, the dose of antidepressant monotherapy may have been too low for some patients. ${ }^{16}$ Furthermore, when there is a higher degree of treatment failure in selected patients before initiating a combined treatment, it may be more difficult to prove greater efficacy with combination treatment. In another recent study, it was concluded that the most robust and predictable benefits of combining antidepressants are limited to a reuptake blocking agents combined with mirtazapine. ${ }^{19}$

In the current study, the duloxetine combination therapy group demonstrated greater improvement on the CGI-S than did the duloxetine monotherapy group. While there are extant studies that examine the effects of venlafaxine, another SNRI, combined with mirtazapine or mianserin, ${ }^{6,20}$ these studies, which compare monotherapy versus combination therapy of antidepressants, seldom included duloxetine. To the best of our knowledge, there is only one study that included duloxetine when comparing antidepressant monotherapy with combination therapy. That study compared efficacy, safety and tolerability of combined duloxetine plus bupropion ( $\mathrm{n}=$ 23) versus duloxetine monotherapy $(n=23)$ in patients with a DSM-IV diagnosis of major depression with atypical features and a history of treatment resistance. This explorative randomized controlled trial indicates that the combination with

Table 4. Incidence of adverse events

\begin{tabular}{|c|c|c|c|c|}
\hline \multirow{2}{*}{ Adverse event (\%) } & Monotherapy $(\mathrm{N}=36)$ & Combination therapy $(\mathrm{N}=46)$ & Total $(\mathrm{N}=82)$ & \multirow{2}{*}{$\mathrm{p}$} \\
\hline & $\mathrm{N}(\%)$ & $\mathrm{N}(\%)$ & $\mathrm{N}(\%)$ & \\
\hline Nausea & $1(2.7)$ & $3(6.3)$ & $4(4.9)$ & 0.63 \\
\hline Dizziness & $1(2.7)$ & $4(8.7)$ & $5(6.1)$ & 0.38 \\
\hline Dry mouth & $2(5.6)$ & $3(6.3)$ & $5(6.1)$ & 1.00 \\
\hline Constipation & $4(11.1)$ & $3(6.3)$ & $7(8.5)$ & 0.69 \\
\hline Headache & $1(2.7)$ & $4(8.7)$ & $5(6.1)$ & 0.38 \\
\hline Sweating & - & - & - & - \\
\hline Loss of appetite & $2(5.6)$ & - & $2(2.4)$ & 0.19 \\
\hline Somnolence & $1(2.7)$ & $7(15.2)$ & $8(9.8)$ & 0.07 \\
\hline Blurred vision & - & - & - & - \\
\hline Palpitation & $1(2.7)$ & $2(4.3)$ & $3(3.7)$ & 1.00 \\
\hline Fatigue & $1(2.7)$ & - & $1(1.2)$ & 0.44 \\
\hline Etc & $3(8.3)$ & $1(2.2)$ & $4(4.9)$ & 0.32 \\
\hline
\end{tabular}


bupropion failed to demonstrate any clear advantage compared with an adjunctive placebo, with response rates of $21.7 \%$ versus $26.1 \%$ in the +placebo and +bupropion groups, respectively. This may be due to the selection of a special sample that is, per se, unlikely to respond to standard antidepressants or their combinations. Similar considerations may contribute to explaining the high drop-out rate in both groups. ${ }^{21}$

In our study, which employed a naturalistic design, there was lower drop-out rate, and a variety of antidepressants was included in the combination regimen. The choice of antidepressant, dosages of antidepressants and the decision as to when to begin combining antidepressants with therapy was solely dependent on the clinician. The dosage of duloxetine was lower than that was reported from previous Western studies. $^{7-13}$ Majority of patients $(93.5 \%)$ in combination group were prescribed with second antidepressant before 4 weeks.

The present study has certain limitations. As the study design was naturalistic, it did not use blind raters nor did it use a placebo. Furthermore, the sample size was modest, assessment and treatment outcome biases related to the use of multiple centers should also be considered when reviewing the results. The last limitation was the short-term follow up period. We were unable to ascertain the superior efficacy of duloxetine combination therapy over a longer timeframe.

Despite these limitations, however, we believed that a multicenter-based retrospective naturalistic study would provide useful information about the efficacy and safety of and other practical aspects of duloxetine combination therapy with other antidepressant.

In conclusion, the present study indicates that duloxetine combination therapy with other antidepressants may be more effective than duloxetine monotherapy. Duloxetine combination therapy with other antidepressant also didn't show severe adverse events in depressed patients. Future studies of duloxetine combination therapy with other antidepressants should evaluate efficacy and tolerability of specific antidepressant combinations with the characteristics of patients who could best benefit from this type of treatment. Furthermore, longitudinal studies that examine the long-term effectiveness as well as safe relapse prevention are needed as are placebo-controlled, multicenter, short- and long-term studies that assess the efficacy and tolerability of duloxetine combination therapy with other antidepressants.

\section{REFERENCES}

1. United States. Depression Guideline Panel., United States. Agency for Health Care Policy and Research. Depression in Primary Care. Washington, D.C.: US Deptartment of Health and Human Services; 1993.

2. Rush AJ, Trivedi MH, Stewart JW, Nierenberg AA, Fava M, Kurian BT, et al. Combining medications to enhance depression outcomes (CO-
MED): acute and long-term outcomes of a single-blind randomized study. Am J Psychiatry 2011;168:689-701.

3. Rush AJ, Trivedi MH, Wisniewski SR, Nierenberg AA, Stewart JW, Warden D, et al. Acute and longer-term outcomes in depressed outpatients requiring one or several treatment steps: a STAR*D report. Am J Psychiatry 2006;163:1905-1917.

4. Practice guideline for the treatment of patients with major depressive disorder (revision). American Psychiatric Association. Am J Psychiatry 2000;157(4 Suppl):1-45.

5. Thase ME. Antidepressant combinations: widely used, but far from empirically validated. Can J Psychiatry 2011;56:317-323.

6. Blier P, Ward HE, Tremblay P, Laberge L, Hebert C, Bergeron R. Combination of antidepressant medications from treatment initiation for major depressive disorder: a double-blind randomized study. Am J Psychiatry 2010;167:281-288.

7. Nemeroff CB, Schatzberg AF, Goldstein DJ, Detke MJ, Mallinckrodt C, $\mathrm{Lu} \mathrm{Y}$, et al. Duloxetine for the treatment of major depressive disorder. Psychopharmacol Bull 2002;36:106-132.

8. Detke MJ, Lu Y, Goldstein DJ, Hayes JR, Demitrack MA. Duloxetine, $60 \mathrm{mg}$ once daily, for major depressive disorder: a randomized doubleblind placebo-controlled trial. J Clin Psychiatry 2002;63:308-315.

9. Detke MJ, Lu Y, Goldstein DJ, McNamara RK, Demitrack MA. Duloxetine $60 \mathrm{mg}$ once daily dosing versus placebo in the acute treatment of major depression. J Psychiatr Res 2002;36:383-390.

10. Detke MJ, Wiltse CG, Mallinckrodt CH, McNamara RK, Demitrack MA, Bitter I. Duloxetine in the acute and long-term treatment of major depressive disorder: a placebo- and paroxetine-controlled trial. Eur Neuropsychopharmacol 2004;14:457-470.

11. Goldstein DJ, Mallinckrodt C, Lu Y, Demitrack MA. Duloxetine in the treatment of major depressive disorder: a double-blind clinical trial. J Clin Psychiatry 2002;63:225-231.

12. Goldstein DJ, Lu Y, Detke MJ, Wiltse C, Mallinckrodt C, Demitrack MA. Duloxetine in the treatment of depression: a double-blind placebo-controlled comparison with paroxetine. J Clin Psychopharmacol 2004:24:389-399.

13. Perahia DG, Gilaberte I, Wang F, Wiltse CG, Huckins SA, Clemens JW, et al. Duloxetine in the prevention of relapse of major depressive disorder: double-blind placebo-controlled study. Br J Psychiatry 2006;188: 346-353.

14. Gartlehner G, Thaler K, Hansen RA, Gaynes BN. The general and comparative efficacy and safety of duloxetine in major depressive disorder: a systematic review and meta-analysis. Drug Saf 2009;32:1159-1173.

15. Hudson JI, Wohlreich MM, Kajdasz DK, Mallinckrodt CH, Watkin JG, Martynov OV. Safety and tolerability of duloxetine in the treatment of major depressive disorder: analysis of pooled data from eight placebo-controlled clinical trials. Hum Psychopharmacol 2005;20:327-341.

16. American Psychiatric Association. Diagnostic Criteria from DSM-IVTR. Washington, D.C.: American Psychiatric Association; 2000.

17. Busner J, Targum SD. The clinical global impressions scale: applying a research tool in clinical practice. Psychiatry (Edgmont) 2007;4:28-37.

18. Rocha FL, Fuzikawa C, Riera R, Hara C. Combination of antidepressants in the treatment of major depressive disorder: a systematic review and meta-analysis. J Clin Psychopharmacol 2012;32:278-281.

19. Rush AJ. Combining antidepressant medications: a good idea? Am J Psychiatry 2010;167:241-243.

20. Thase ME. Combined antidepressant strategies are not more effective than vigorous escitalopram monotherapy: results of the CO-MED study. Curr Psychiatry Rep 2011;13:434-436.

21. Fornaro M, Martino M, Mattei C, Prestia D, Vinciguerra V, De Berardis $\mathrm{D}$, et al. Duloxetine-bupropion combination for treatment-resistant atypical depression: a double-blind, randomized, placebo-controlled trial. Eur Neuropsychopharmacol 2014;24:1269-1278. 